\title{
Robert Wise's The Day the Earth Stood Still (1951) and Interplanetary Emissary Klaatu Are Not Anti-Atomic: A Reassessment of the Filmic Evidence
}

\author{
Anton Karl Kozlovic
}

check for

updates

Citation: Kozlovic, Anton Karl. 2021 Robert Wise's The Day the Earth Stood Still (1951) and Interplanetary

Emissary Klaatu Are Not

Anti-Atomic: A Reassessment of the Filmic Evidence. Humanities 10: 107. https:/ /doi.org/10.3390/h10040107

Received: 16 August 2021

Accepted: 15 September 2021

Published: 24 September 2021

Publisher's Note: MDPI stays neutral with regard to jurisdictional claims in published maps and institutional affiliations.

Copyright: (C) 2021 by the author Licensee MDPI, Basel, Switzerland. This article is an open access article distributed under the terms and conditions of the Creative Commons Attribution (CC BY) license (https:// creativecommons.org/licenses/by/ $4.0 /)$.
Department of Media and Communication, Deakin University, Burwood, VIC 3125, Australia; akozlovi@deakin.edu.au

\begin{abstract}
Inspired by a 1940s short story by Harry Bates, scripted by Edmund H. North, and directed by Robert Wise, The Day the Earth Stood Still (1951) is a science fiction cult classic. Of all its diverse interpretations, a commonly adopted reading influenced by the dawning of the Atomic Age parades it as an anti-nuclear exemplar starring alien emissary Klaatu visiting Earth with his robot companion Gort to (supposedly) suppress humanity's atomic progress. However, upon a close forensic inspection of the film and commentator comments, this anti-atomic claim is resoundingly rejected. Utilizing humanist film criticism as the guiding analytical lens (i.e., looking inside not outside the frame), plus a selective review of the critical literature, it was demonstrated that: (a) there is a dearth of atomic iconography and dialogue, (b) there is no mention of banning atomic energy or weapons, (c) Earth's atomics are nascent and not serious threats to the Federation, and (d) Klaatu is not anti-atomic but proudly pro-atomic. Overall, this SF film is strongly pro-nuclear in intention, word, and deed, which was frequently misinterpreted due to faulty film criticism, invented facts, and jumping to conclusions, and thus in need of academic correction. Further research into alien first-contact scenarios, robotic artificial intelligence, and the moral make-up of the SF universe is warranted and long overdue.
\end{abstract}

Keywords: The Day the Earth Stood Still (1951); science fiction film; Robert Wise; Michael Rennie; Klaatu; Gort; Prof. Barnhardt; atomic; nuclear

"... You Will Forgive Me If I Speak Bluntly"

-Klaatu addressing his earthly audience

\section{Introduction: A Much Loved But Seriously Misunderstood Cult Classic}

Inspired by a 1940s short story by Harry Bates entitled Farewell to the Master, scripted by Edmund H. North (1951), and directed by American filmmaker Robert Wise, The Day the Earth Stood Still (1951) is a classic science fiction (SF) film about alien first-contact. A humanoid emissary (with robot companion), representing an interplanetary Federation, visited Earth (in a saucer-shaped spaceship) espousing peace and good will and offering cosmic membership, sweetened with a technological gift of inestimable value. He eagerly wanted to address the entire planet but instead was shot and wounded, imprisoned, and after escaping, lived incognito amongst the people whilst being hunted. He made friends and was eventually betrayed by one of them, killed, resurrected, then promptly returned home after updating humanity about their precarious cosmic situation. However, he offered humanity a solution, either choose the path of peace or face global annihilation by robot policemen who were automatically triggered if earthlings refused to shun their bellicose ways.

The film became an "American cult favorite" (Bell-Metereau 2006, p. 125) and made "audiences feel that there was something serious about science fiction" (Zebrowski 1974, p. 39). It won the Golden Globe Award for the Best Film Promoting International Understanding (Fischer 2000, p. 686) and was deemed "the most interesting and subtle science-fiction film that Hollywood produced in the 1950s ... astonishingly thoughtful by 
the standards of the time" (Freedman 1998, p. 316). However, as actress Patricia Neal (who played Helen Benson) reminisced: "No one involved in the making of The Day the Earth Stood Still realized that it would become the hallmark science fiction film" (Shearer 2006, p. 114) and would become a genre "benchmark by which all other alien movies are judged" (Mann 2001, p. 355). The American National Film Registry selected it for being culturally, historically, or aesthetically significant (Eagan 2010, pp. 446-48), and even rocket scientists at NASA's Jet Propulsion Laboratory regularly screened it for its insights into alien-human relations (Longuski 2007, p. 5).

Yet, despite its popularity, cultic status, and numerous accolades, both professional and lay commentators considered that it had illustrated everything from sonics (CrannyFrancis 2007) to gender issues (George 2008), politics (Shaw 1998) to religion (Cowan 2009), history (Barone 1996) to pop culture science (Luokkala 2019), but by doing so, they sometimes misconceived, misunderstood, or misread the actual filmic facts in the process. Regrettably, such is the case concerning whether this 1950s visitation (not invasion) film, and alien emissary Klaatu (Michael Rennie) who represented an interplanetary Federation of other intelligent worlds making first-contact with humanity, actually stood for, or against, Earth's atomics. ${ }^{1}$ Determining the answer to this question is the specific focus of this investigation. Since any good interpretation can never contradict the basic facts of the film, thereby distorting its meaning, misdirecting viewer expectations, and compromising its critical reception, a close forensic reading of the film and related commentator claims was performed and the insights discovered are explicated herein.

The critical cinema and Cold War literatures were selectively reviewed and integrated into this text to enhance narrative coherence (albeit, with a strong reportage flavor) utilizing the analytical lens of textually-based humanist film criticism (i.e., examining the textual world inside the frame, but not the world outside the frame) to extract its meaning (Bywater and Sobchack 1989, pp. 24-47). This frequently underutilized film analysis methodology is applicable to all movie genres ranging from science fiction (Telotte 2001, pp. 35-38) to literary autobiography (Johnson 2007). It assumes audiences are cultured, accept the cinema as fine art, and have seen the movie(s) under discussion. Its pedagogic function is to identify noteworthy incidents and foster critical commentary rooted in primary and secondary sources (e.g., the nominated movie(s), memoirs, autobiographies, biographies, film books, magazines, scholarly journals), plus the tracking of themes, motifs, symbols, tropes, and topoi. All of which makes this methodology apt for the author's intended research task.

\section{Anti-Atomic Readings of the Film: Accurate? True? Fair?}

At the risk of leaning towards the polemical, numerous commentators throughout the decades have claimed that The Day the Earth Stood Still (Wise 1951) is an anti-atomic film and that the interplanetary alien Klaatu, with robot bodyguard Gort (Lock Martin), specifically came to Earth to discourage, suppress, if not stop all together, scientific progress in Earth atomics and its rocket delivery system. For example, Alan G. Frank (1974, p. 148) claimed that Gort was "programmed to destroy the world should earth continue to make atomic tests" (my emphasis), and elsewhere Frank (1976, p. 144) claimed: "Rennie [Klaatu] had come to warn the world to discontinue their tests of atomic weapons" (my emphasis). Similarly, Jeff Rovin (1977, p. 86) claimed that: "an alien being [Klaatu] put a forcible halt to earth's nuclear experimentation" (my emphasis), whilst Lawrence H. Suid (2002, p. 223) claimed that: "an alien arrives on the Ellipse in Washington to warn the world that it must stop the spread of nuclear weapons or face destruction from a more advance civilization that will not tolerate atomic warfare in the universe" (my emphasis).

Furthermore, Daniel Wojcik (2003, p. 275) said, "the Christ-like alien Klaatu forewarns of the threat of atomic bombs" (my emphasis), and Possamai and Possamai-Inesedy (2014, p. 104) claimed: "This 1951 cult classic film was a clear wake-up call to the disaster potential of a nuclear war. In this narrative, an alien [Klaatu] comes to Earth to deal with the misuse of nuclear power" (my emphasis). Carole M. Cusack (2014, p. 345) claimed that "Klaatu's 
mission is to inform humanity that violence, and the threat of nuclear war in particular, is alarming the peaceful citizens of other planets" (my emphasis). Copier and Stichele (2016, p. 161) characterized this SF movie as a 1950s disaster film "where the atomic bomb and the Cold War ... feature prominently" (my emphasis).

Interpreted somewhat more creatively, Paul Boyer (2016, p. 77) claimed that "space visitor Michael Rennie [Klaatu] warns earthlings to form a global union to enforce peace or face annihilation, since their atomic tinkering threatens not only Earth but also the cosmos itself" (my emphasis). Christine Cornea (2017, p. 162) claimed that "the central narrative conceit in The Day the Earth Stood Still [Wise 1951] is remarkably similar to the Flying Disc Men [sic] from Mars serial [(Brannon 1950)]: both feature an alien visitor sent to police the human use of atomic technologies" (my emphasis). Kenneth T. Walsh (2017, p. 143) ramped up the fear factor by claiming: "The alien [Klaatu] warns humans to get along and end their fixation with nuclear weapons, or be destroyed" (my emphasis). William Sims Bainbridge (2017, p. 159) also elaborated upon this atomic premise by claiming that "an alien visitor [Klaatu] warns Earth that it must not develop rocket-delivered nuclear weapons" (my emphasis), whilst Barry B. Luokkala (2019, p. 273) similarly said: "The visitor [Klaatu] warns the people of Earth against spreading their use of nuclear weapons into outer space" (my emphasis), as if atomics was an already established and mature terrestrial industry. In short, Earth's atomic weaponry, nuclear testing, and tinkering with rocketry were viewed as secular equivalents of Earth evils now in urgent need of suppressing, banning, or outright elimination (along with planet Earth and humanity). Is this true? What filmic evidence exists to verify Earth's supposed atomic fixation?

The author argues that these anti-atomic comments are serious misreadings of Robert Wise's actual film, as distinct from: (a) Harry Bates's 1940s short story published in the magazine Astounding Science-Fiction, which did not have a nuclear-weapons theme, being more concerned with the relationship between the green metal robot master, Gnut, and its murdered biological companion, Klaatu (Bates 1940, pp. 58-87), (b) Edmund H. North's (1951) film script that differs significantly from Bates's short story by reversing character roles and intentionally engineering Christic parallels (von Gunden and Stock 1982, p. 44), (c) Scott Derrickson's (2008) ecologically themed remake that significantly differs from both Bates's and Wise's interpretations (Çetiner-Öktem 2019), or (d) the Cold War nuclear zeitgeist interpretation commonly foisted upon it by well-meaning critics (Mathis 2013), supposedly occurring because of the dawning of the Atomic Age precipitated by the American-led Manhattan Project (1942-1946) designed to develop atomic weapons, and the subsequent United States detonation of two nuclear bombs over the Japanese cities of Hiroshima and Nagasaki (6th and 9th August 1945, respectively).

Furthermore, the author claims that Robert Wise's The Day the Earth Stood Still (1951) is not anti-atomic, with alien emissary Klaatu being proudly pro-atomic in intention, word, and deed; albeit, the extremely muted references to atomics therein can be considered a faint echo of the historical situation seeping in during the short story-to-silver screen adaptation process to (presumably) make it a contemporary (1950s style) film product. Thus, those researchers who embedded the film in this remote historical context may not be necessarily incorrect at this surface level of analysis, until they perform a deeper examination without being burdened by those pre-digested historical assumptions unverified within the film. Indeed, the anti-atomic claims are effectively neutralized when one discovers that these interpretations have been influenced more by later (faulty) film criticism than found within the film itself.

What Robert Wise's film actually says/displays/reveals (as distinct from dissenting commentator claims) is vitally important, as is exploring what is logically missing, plotwise, given the strident atomic claims made about the film for decades and repeatedly (and unthinkingly) regurgitated. The following investigation will reveal currently undervalued insights that will challenge previously taken-for-granted understandings. This exploration will be organized under the following four headings, namely: (a) There is a Dearth of Atomic Iconography and Dialogue, (b) There is No Mention of Banning Atomic Energy or 
Weapons, (c) Earth's Atomics are Nascent and Not Serious Threats to the Federation, and (d) Klaatu is Not Anti-Atomic but Proudly Pro-Atomic. Each proposition is explicated below (with minor repetition and content overlaps for the sake of clarification and completeness) accompanied by copious illustrative screen shots for verification purposes.

\section{There Is a Dearth of Atomic Iconography and Dialogue}

Given the above-documented assertions of Earth's abundant atomic technology and its supposed narrative centrality, it is remarkable to find that The Day the Earth Stood Still (Wise 1951) actually suffers a serious dearth of atomic iconography and dialogue traditionally associated with this radioactive subgenre (Mathis 2013; Shaheen 1978; Shapiro 2002), whether as popular cinema, news, or documentary (Strada 1986; Taylor 2003; Weart 1988). Yet, what is revealed is scant. For example, while visiting Prof. Jacob Barnhardt (Sam Jaffe), the business-suited Mr. Carpenter (actually the alien Klaatu's Earthman disguise; hereafter Carpenter-Klaatu) candidly reveals, "We know from scientific observation that your planet has discovered a rudimentary kind of atomic energy" (my emphasis; see Figure 1), which implies a relatively recent breakthrough, not technological maturity, practical application, or widespread proliferation (let alone safely into outer space or orbiting Earth).
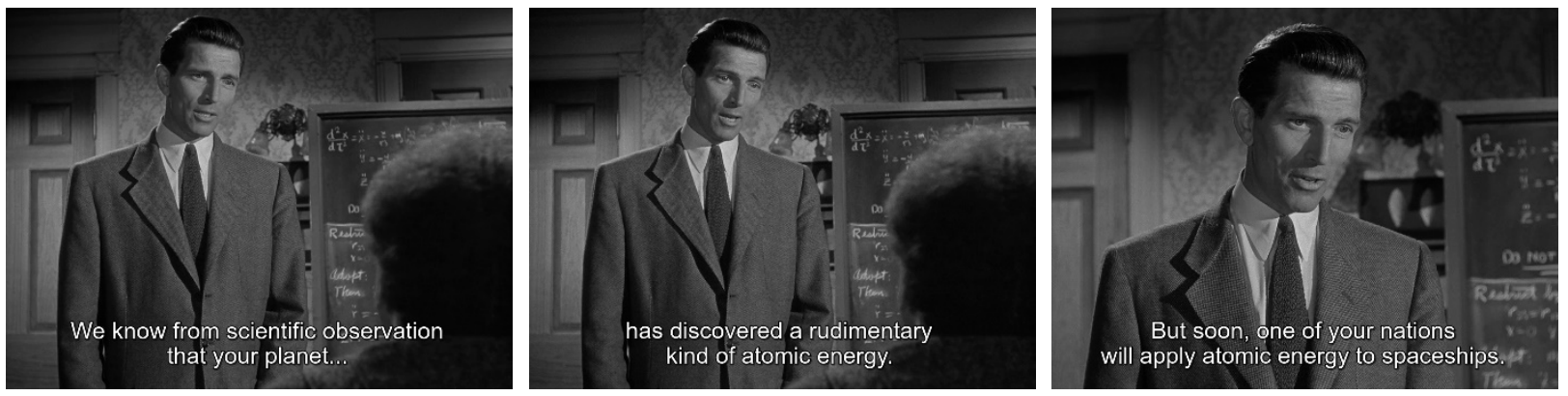

Figure 1. Klaatu's 'atomic energy' comments. The Day the Earth Stood Still @ 20th Century Fox. All Rights Reserved.

The embryonic state of Earth's rudimentary atomics is strongly borne out by the onscreen avoidance of multiple scenarios that could have revealed more mature atomics, if they existed. Albeit, what exactly a 1947-1951 audience would expect from an atomic film is problematic, but no doubt generations of contemporary audiences and critics marinated in nuclear iconography ever since would expect a wide array of possibilities. Therefore, it is surprising to discover that within The Day the Earth Stood Still (Wise 1951) there are (in no particular order):

- No images of nuclear power plants (whether viewed from the sky, the road, or interior shots).

- No images of glowing nuclear fuel rods bubbling away in heavy water reactors designed to dampen its deadly radiation.

- No scientists manipulating nuclear fuel rods with remote controlled electro-mechanical arms or radiation-proof gloves.

- No scientific or military personnel wearing bulky radiation suits plodding around inside nuclear power plants, weapon establishments, technical laboratories, or recent nuclear devastation sites.

- No decontamination shower scenes, pre- or post-atomic inspection (whether the personnel are naked, near naked, wearing clothing, and/or donning hazmat suits with life-support equipment).

- No scenes of the President conferring with his military staff debating their nuclear status, scientific options, atomic policies, or military-cum-nuclear disaster preparations, protocols, and political responses (whether past, present, or future-focused).

- No scenes of the President's military aide in the background holding any precursor to the nuclear football whilst waiting for the President (as commander-in-chief of the armed forces) to potentially push the missile launch button. 
- No scenes of commercial spies or foreign agents attempting to infiltrate nuclear establishments, plant intelligence-gathering bugs to steal secrets, or sabotage atomic equipment, along with any dedicated government agents (open or undercover) hunting them and deploying counter-terrorism strategies.

- No nerdy scientists (wearing thick eyeglasses and white laboratory coats?) explaining the danger of atomics and associated weaponry to an audience (whether scientific, military, or civilian, public or private, personally, or via educational-cum-marketing media).

- No duck-and-cover newsreels (for safety or propaganda), with or without civilian rehearsals to highlight the nuclear threat potential.

- No doomsday clocks (analogue or digital) showing the relative risk of nuclear war to human civilization, health, or planetary survival.

- No nuclear warning scenes, whether: (a) verbal dialogue (e.g., direct, indirect, prerecorded, or flashback), (b) urgent alarms (e.g., wailing sirens, klaxon horns, Geiger counter clicking, or frenetically beeping speakers with or without rapidly blinking panel lights), or (c) nuclear signage (e.g., iconic yellow-and-black trefoil hazard symbols, skull-and-bones graffiti, or publicly flaunted anti-nuclear protestor placards).

- No images of nuclear rockets sitting in their silos ready for launching (with or without creeping pre-launch vapors), or banks of stockpiled nuclear warheads waiting to be attached to missiles (with or without technicians milling around giving specialist assistance).

- No scenes of atomic bombs being dropped, or nuclear war being experienced, imagined, role-played, detected, verified, then rapidly responded to (whether directly or indirectly, officially or independently).

- No real or imagined scenes of military personnel in control rooms, secured bunkers, missile sites, submarines, etc., ritually opening sealed envelopes (or their equivalents) to obtain and verify pre-prepared nuclear launch codes.

- No scenes of military personnel seeking higher-up confirmation of the attack-cumlaunch order before entering their nuclear launch codes.

- No scenes of military personnel placing their personal security keys into launch keyholes strategically located away from each other and then turned simultaneously to arm the onsite atomic weaponry.

- No scenes of mobile missile launchers or landlocked metal doors and/or flaps opening (whether mechanically or explosively), and their nuclear missiles fired from launch tubes, tracks, pads, trucks, or silos.

- No scenes of fire-and-fury as the launched missiles streak through the skies towards their targets with accompanying flames and smoke-cum-vapor trails left behind to scar the sky.

- No government, allied, or enemy war rooms displaying potential (or already launched) in-bound/out-bound missile trajectories with associated telemetry (gathered by radar domes, microwave dishes, spotter planes, satellite uplinks, etc.) to provide real-time detonation data.

- No scenes of military personnel, scientists, or civilians rapidly donning radiation outfits and gathering necessary equipment (e.g., Geiger counters, nuclear toolboxes, first aid kits) once getting confirmed (or dry run) radiation leakage alarms, or imminent nuclear attack warnings.

- No scenes of people cramming into nuclear fall-out shelters (whether public, private, or quickly improvised), typically accompanied by wailing warning sirens or urgent public service announcements (via radio, television, telephone, teleprinters, or public address systems).

- No scenes of the military (whether domestic or foreign) launching defensive aircraft and anti-missile rockets from silos, land vehicles, aircraft carriers, submarines, or orbiting satellites in order to neutralize enemy attacks. 
- No dramatic incidents of personal bravery, such as soldiers, scientists, or citizens heroically sacrificing themselves to save innocent others (e.g., by exposing themselves to lethal doses of radiation, without any protective gear, to stop equipment from melting down and exploding).

- No bomb dropping-cum-ferocious detonation scenes with yellowish atomic mushroom clouds forming, growing heavenwards with blood red skies, and later lingering ominously after the radiating blast wave violently consumed everything in their paths.

- No dramatic scenes of buildings, cars, equipment, animals, mannequins, or real people being injured or vaporized by bomb blasts (with or without silhouetted scenes of victims being dramatically highlighted).

- No panoramic post-detonation scenes (real or imagined, current or flashback) whether they be: (a) radioactive fallout aggressively glowing, cooling down, or dead-butdangerous, (b) iconic atomic by-products (e.g., seas of glass formerly sandy deserts, amorphous molten lumps formerly cars, bridges, and buildings), (c) ferocious, geographically abnormal weather patterns (involving rain, snow, wild winds, thunder, violently discharging lightening), (d) slow ecological recovery (with or without malformed flora and fauna), (e) blackened corpses or bleached bones (human and animal), (f) deformed or grossly mutated humans and animal species, (g) social decay-cumcollapse of human civilization, (h) increasingly aggressive-cum-predatory nature (plant, animal, and insect), (i) deteriorating architectural remnants of devastated installations, towns, and cities, or (j) archaeological digs within "forbidden zones" revealing evidence of ancient atomic devastations (minor or major), whether officially acknowledged or secretly suppressed for sociocultural, political, or religious reasons.

To reiterate, the above myriad scenarios are logical nuclear-related possibilities that were not portrayed within Robert Wise's SF film. Why not?

Compared to 1950s non-SF films The 49th Man (Sears 1953), Hell and High Water (Fuller 1954), and Port of Hell (Schuster 1954), which dealt explicitly with nuclear terrorism, the Cold War, and American anticommunism (Hunter 2009), the avoidance of any of the above shopping list of atomic scenarios within Wise's movie is disturbingly incongruous. Their non-existence clearly contradicts commentator claims that The Day the Earth Stood Still (Wise 1951) supposedly features, and quite "prominently" (Copier and Stichele 2016, p. 161), "atomic technologies" (Cornea 2017, p. 162), "tests of atomic weapons" (Frank 1976, p. 144), and "atomic warfare" (Suid 2002, p. 223) supposedly because "the early 1950s had displaced Cold War paranoia onto science fiction films such as The Day the Earth Stood Still ([Wise] 1951) and Invasion of the Body Snatchers ([Siegel] 1956)" (Hefner 2014, p. 11).

More pertinent, these grossly exaggerated commentator claims did not occur within Wise's film simply because they were logically premature given the story's foundational premise of Federation intervention before Earth had serviceable atomics, before the existence of any rival atomic powers (as opposed to normal military opponents), and before Earth had interstellar flight capabilities (let alone proven and practical). At least physicist Sidney Perkowitz (2010, p. 202) highlighted the film's lack of Earth's atomics when he repeatedly reported: "Nor does the film feature nuclear explosions" because "The Day the Earth Stood Still (1951) is different, presenting moral issues instead of explosions" (Perkowitz 2010, pp. 96-97), and thus "makes its point without showing nuclear destruction" (Perkowitz 2010, p. 98), if for the wrong reasons.

Within Wise's film (and not the commentators' imaginative extrapolations), the closest the storyline gets to any Earth-based atomics (whether energy, bombs, or infrastructure) linked to interplanetary technology is Carpenter-Klaatu's brief admission to Prof. Barnhardt, namely: "We know from scientific observation that your planet has discovered a rudimentary kind of atomic energy ... [and that] one of your nations will apply atomic energy to spaceships" (my emphasis; see Figure 1); in short, (a) an existing rudimentary technology (i.e., immature) and (b) a predicted future Earth technological capability (i.e., non-existent but feasible). 
There is nothing else within Robert Wise's (1951) film that demonstrates, discusses, highlights, corroborates, or underpins this claim of "a rudimentary kind of atomic energy" (but which is treated as truthful), nor were any clues given about how their "scientific observation" of Earth was gathered. Logically speaking, it could have been achieved by: (a) monitoring-cum-analyzing Earth radio broadcasts (which Klaatu told Mr. Harley [Frank Conroy] they did "for a good many years" to learn Earth's languages), (b) the Federation spied upon humanity (e.g., scientists, government officials, the military) using alien intelligence-gathering technology akin to Klaatu's far-seeing gift for the President, (c) direct observation via Federation spaceships preceding first-contact, (d) all three previous tactics, or (e) other (unrevealed) alien methods, techniques, or strategies.

And so, despite scant-cum-absent atomic references, missing nuclear iconography, and eschewed logical atomic scenarios, it is surprising to find that many commentators creatively extrapolated imagined nuclear facts into an urgent need to ban Earth atomics. For example, David Eldridge (2006, p. 295) claimed that: "The Day the Earth Stood Still (1951) posited the threat of global annihilation should politicians with their fingers on the [nuclear] button not come to their senses," or the concomitant claim: "The fact that the U.S. and Russia now have nuclear weapons makes Klaatu's mission all the more urgent" (Stanley et al. 2018, p. 208; my emphasis). Although both claims are potential future scenarios, they did not exist within the film's present-focused timeframe; presumably they are personal perceptions of the fears and anxieties associated with the real-world dawning of the Atomic Age reflected back into their (erroneous) readings of the film. However, what about banning atomic energy or weapons within its storyline?

\section{There Is No Mention of Banning Atomic Energy or Weapons}

Surprisingly, the words "nuclear" and "bomb" do not occur within the film, whilst the word "bombs" occurs only once when young Bobby Benson (Billy Gray) spontaneously associated it with "atomic power" (my emphasis) when asking Carpenter-Klaatu what powered the alien spaceship (see Figure 2). Furthermore, the word "atomic" occurs just three times, namely: (a) when Klaatu told Bobby that the spaceship's energy source was "atomic power" (my emphasis; see Figure 2), (b) when Klaatu told Prof. Barnhardt that humanity had a "rudimentary kind of atomic energy" (my emphasis; see Figure 1), and (c) when Klaatu told Barnhardt that "soon one of your nations will apply atomic energy to spaceships" (my emphasis; see Figure 1). Significantly, no mention is made of an "atomic bomb" or any other type of nuclear label-cum-weapon of mass destruction (e.g., "A-Bomb," "hydrogen bomb", "H-bomb," "nuclear bomb," "neutron bomb," "plutonian bomb," "fission bomb," "thermonuclear bomb"), although a potential word or topic one could expect from Klaatu, Prof. Barnhardt, the President, the military, the police, the media, scientists, crowds, etc.
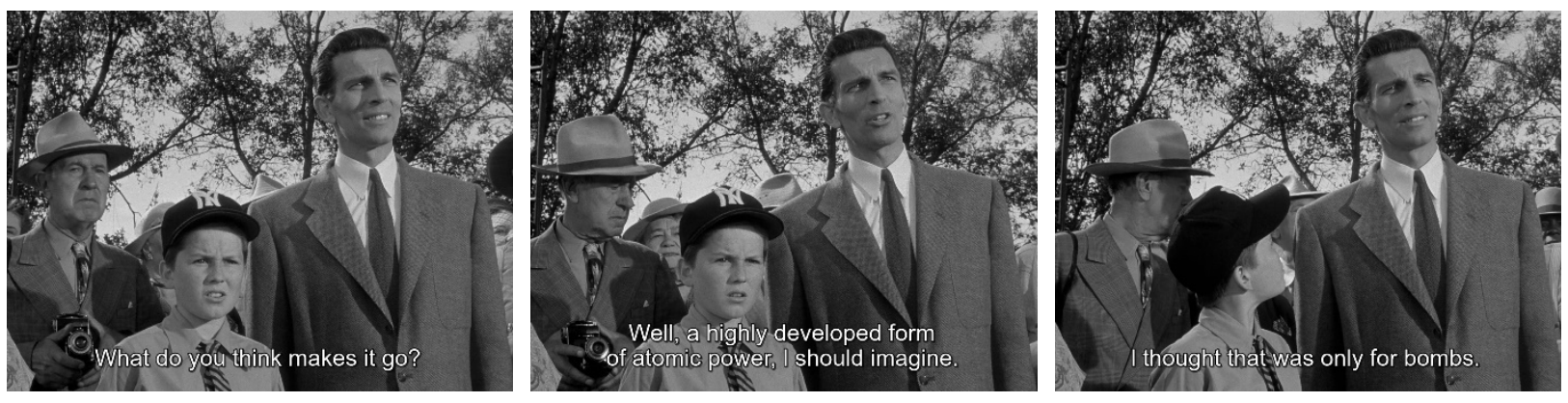

Figure 2. Bobby Benson's 'bombs' comment. The Day the Earth Stood Still @ 20th Century Fox. All Rights Reserved.

Furthermore, Jungkyu Suh (2021, p. 39) claimed that "technologically superior and militantly pacifist aliens descend from the sky and enforce an absolute ban on nuclear weapons on Earth" (my emphasis), but nowhere in the film does Klaatu do so. Nor does he "stop the world from using atomic weapons" (Frank 1982, p. 43; my emphasis) or put "a forcible halt 
to earth's nuclear experimentation" (Rovin 1977, p. 86; my emphasis), let alone "bring the world to a realization that their playing with uncontrolled atomic fission could only lead to total devastation" (Frank 1978, p. 72; my emphasis), or in any other way limit the usage, production, application, or development of Earth's currently "rudimentary kind of atomic energy" (my emphasis).

It is disappointing to discover that this crucial film fact is frequently overlooked by commentators, but more worrying are those persons who make anti-atomic statements on Robert Wise-Klaatu's (supposed) behalf. For example, Christine Cornea (2017, p. 163) argued that "a film like The Day the Earth Stood Still (1951) displayed a more questioning attitude toward technological development, stressing the dangers inherent in the militarisation of technology, in the deployment of nuclear weaponry" (my emphasis), whilst Jon Towlson (2014, p. 62) claimed that the film "dealt with fears arising from the arms race and the threat of nuclear annihilation" (my emphasis). However, yet again, no nuclear weapon deployment, nuclear annihilation, or atomic militarization issues were ever discussed within the film.

Somewhat worrying, John Brosnan (1978) went as far as to rewrite Klaatu's famous departing soliloquy by spuriously adding atomic technology into his admonishment of humanity's bad behaviors. Brosnan confidently claimed (from his faulty memory, or notes roughly written in the dark, or without the benefit of a VHS tape recorder?):

When the soldiers and scientists arrive on the scene the alien [Klaatu] delivers his message which concludes with the words: 'Soon one of your nations will apply atomic power to rockets. Up to now we have not cared how you solved your petty squabbles. But if you threaten to extend your violence this Earth of yours will be reduced to a burnt out cinder (p. 84; my emphasis). ${ }^{2}$

However, what the film's Klaatu actually said (in appropriately truncated form) was:

The Universe grows smaller every day, and the threat of aggression by any group, anywhere, can no longer be tolerated ... It is no concern of ours how you run your own planet. But if you threaten to extend your violence, this Earth of yours will be reduced to a burned-out cinder" (my emphasis; see Figure 3).
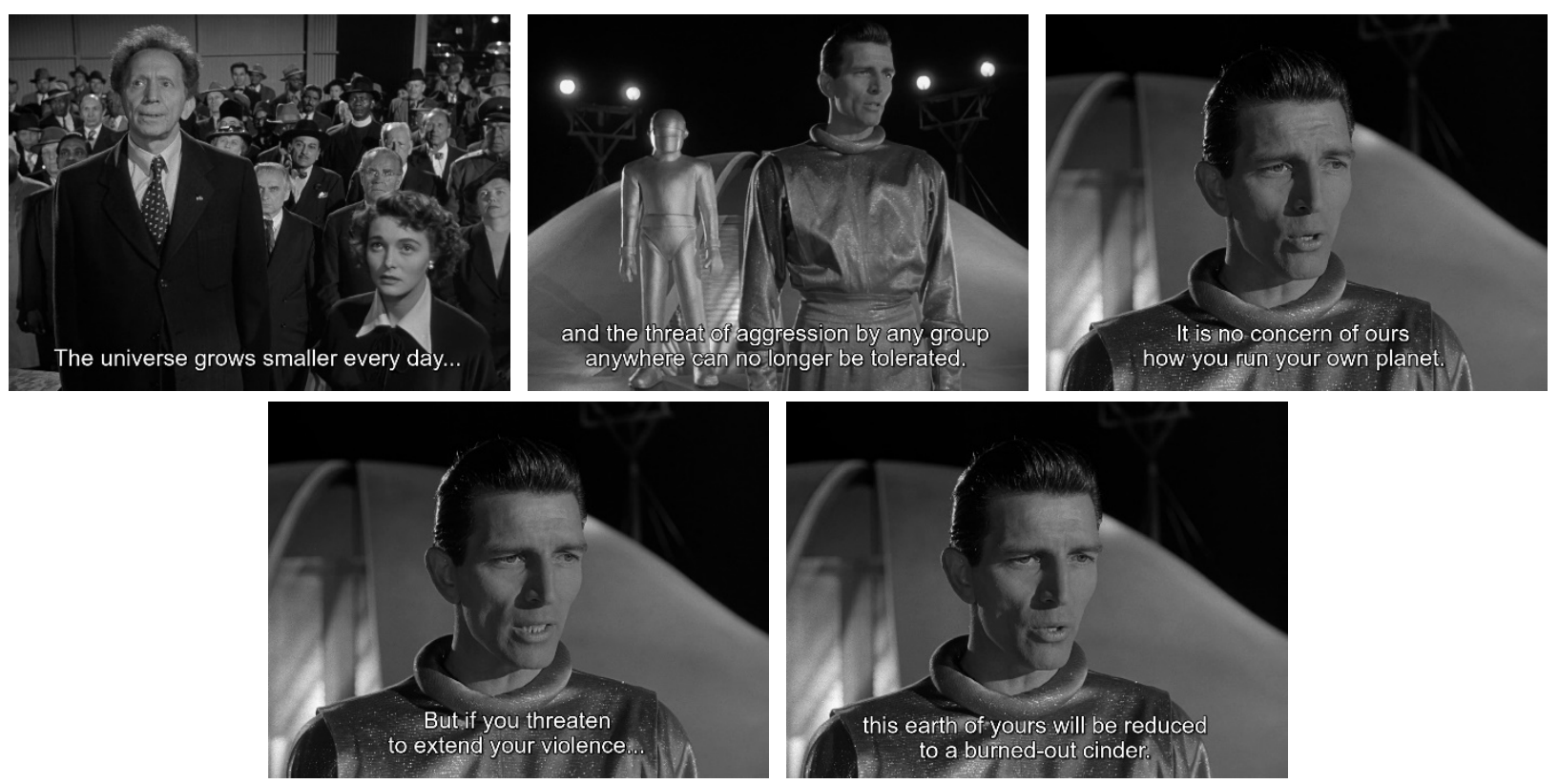

Figure 3. Klaatu's sole concern about 'aggression' and 'violence'. The Day the Earth Stood Still @ 20th Century Fox. All Rights Reserved.

Brosnan had substituted "atomic power" and "rockets" (i.e., Earth technologies) in exchange for Klaatu's actual concern with human "aggression" and "violence" (i.e., anti- 
social behaviors) as if they were interchangeable and unproblematic equivalents. They are not because they are incommensurable. It was a classic category mistake of comparing apples with oranges.

Regrettably, Brosnan's erroneous reading was not an isolated incident. Joyce A. Evans (1998, p. 69) also significantly rewrote Klaatu's departing soliloquy when she stated: "Anything resembling nuclear violence will be punished by the obliteration of the planet. He [Klaatu] cautions that our international disputes and our development of nuclear weaponry endanger the entire universe" (my emphasis). Elsewhere she claimed, "The Day the Earth Stood Still (1951) presents a cautionary tale concerning atomic annihilation and the loss of social control over technology" (Evans 1998, pp. 68-69; my emphasis). In short, Evans (erroneously) added the catastrophic consequences of weaponized atomics, the (supposed) loss of social control, and its (grossly exaggerated) potential impact upon the "entire universe," instead of reiterating Klaatu's actual concern about human aggression and violence. Even Keanu Reeves who played Klaatu in Scott Derrickson's (2008) remake understood this basic fact about the original film. As he stated: "Klaatu came and was saying cease and desist with your violence. If you can't do it yourselves we're going to do it" (quoted in Rosewarne 2020, p. 265) (my emphasis).

Consequently, Klaatu's warning about Earth being reduced to a "burned-out cinder" is the inevitable, automated, robotic consequence "if Earth's violence spreads into space" (Dotson 2009, p. 10; my emphasis). Klaatu's "warning is simple: the earth will be destroyed if it seeks to extend its violent ways beyond earth" (Booker 2001, p. 134; my emphasis), "all Klaatu asked is that the earth give up its aggressive ways only when venturing into space" (George 2000, p. 81; my emphasis). However, Sidney Perkowitz (2010, p. 3) erroneously interpreted this as just being "very careful with nuclear weapons" (my emphasis), thus prompting Klaatu to (supposedly) issue "a chilling warning about the consequences of misusing nuclear weapons" (Perkowitz 2010, p. 9; my emphasis). However, Klaatu never mentions nuclear weapons within Robert Wise's (1951) film.

Furthermore, anti-social behaviors such as human aggression and violence are not limited to the irresponsible deployment of atomics (weaponized or not; military or domestic). Humans can be just as aggressive and violent using non-nuclear instruments, such as deploying: (a) traditional military armaments (e.g., flame-throwers, tanks, artillery), (b) biological weapons (e.g., plagues, genetic manipulation, reproduction blockers), (c) environmental degradation processes and agents (e.g., deforestation, rapacious mining, pollution), or (d) the disrespectful (mis)treatment of extra-terrestrial sociocultural practices, alien religious beliefs, or non-human moral foundations.

In short, Klaatu did not want humanity to extend their aggression and violence beyond Earth into the Federation's proverbial backyard as a consequence of their forthcoming mature rocketry powered by atomic energy that would enable humanity to physically reach the far-flung Federation planets. The shrinking distance interpretation of Klaatu's following departing comment, namely: "The Universe grows smaller every day," is supported by two 1950s film reviewers. Malcolm D. Rivkin (1951, npn) of The Harvard Crimson said, "Now that the earthmen have rocket power almost within their grasp, the space people are afraid that aggression will spread to other hemispheres" (my emphasis), and Stal (1951, p. 6) of Variety similarly said, "now that they are experimenting with rockets, [Earth-people] may soon be able to carry their aggression into outer space" (my emphasis). Significantly, these two reviewers never mentioned atomics (whether bombs, power, or energy), but instead pondered the forthcoming alien-contact consequences of antisocial human behavior.

The anonymous reviewer, Variety Staff $(1951, \mathrm{npn})$, of Variety also eschewed the topic of atomics and instead focused upon the Federation's real concern, namely: "They have come to warn the earth's people that all other inhabited planets have banded together into a peaceful organization and that peace is being threatened by the wars of the earth-people" (my emphasis), and upon arrival, Klaatu's "findings of constant bickerings and mistrust aren't too favorable for the earth's humans" (my emphasis). Whilst Bosley Crowthers (1951, npn) of The New York Times playfully said of its two spaceship pilots, Klaatu and Gort, "you'd 
hardly expect them to split an infinitive, let alone an atom or a human head," and then totally ignored atomic bombs, power, or energy thereafter in this (indirectly acknowledged) Atomic Age film.

\section{Additional Erroneous Readings of the Film}

Joyce A. Evans (1998, p. 126) claimed that "The Day the Earth Stood Still (1951), stressed the destructive force of atomic weapons" (my emphasis), but no Earth-built "atomic weapons" existed during Klaatu's first-contact, let alone did the film offer any audiovisual forays stressing this "destructive force" (see Section 3). Furthermore, Evans confused Earth's technological power with the Federation's superior technological power because the stressing of any "destructive force" was not accomplished by earthlings, but rather by the alien Klaatu, four times, and without mentioning any atomics. It first occurred when a frustratedcum-impatient Klaatu angrily asked Prof. Barnhardt if he needed to take "drastic action," "violent action," in order to have a public hearing. To the curious-cum-alarmed professor, Klaatu seriously suggested, "Levelling New York City perhaps? Or sinking the Rock of Gibraltar" (i.e., dramatic violence as an alien calling card). Instead, he neutralized Earth's electricity worldwide (with some remarkable exceptions- "hospitals, planes in flight. That sort of thing") for precisely half an hour to generate human fear and insecurity, all of which inherently implies serious destructive, and non-destructive, force at Klaatu's command.

Secondly, when Klaatu assured Prof. Barnhardt that the elimination of Earth would be the unavoidable outcome if his peace proposal was rejected (i.e., humanity did not curb its proclivity for "threatening danger"). Such talk of planetary obliteration again inherently implies serious destructive force at Klaatu's command, which was reinforced dialogically and behaviorally when the mildly shocked Prof. Barnhardt, who was initially standing, slowly sinks into his desk chair and worryingly asked Klaatu, "Such power exists?" and the soft-spoken but deadly serious Klaatu replied, "I assure you, such power exists" (see Figure 4).
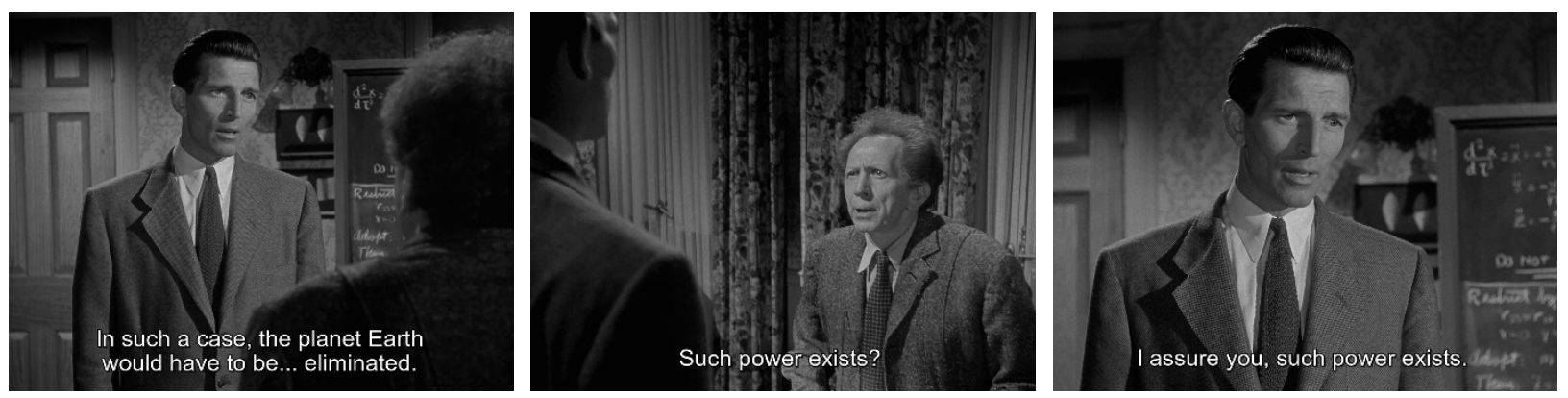

Figure 4. The shocking Klaatu-Barnhardt exchange. The Day the Earth Stood Still @ 20th Century Fox. All Rights Reserved.

Thirdly, sitting inside the Yellow Cab during their tense taxi ride to the scheduled spaceship meeting (whilst fleeing the hotly pursuing military), a worried Klaatu pondered what Gort might do if he died. When Helen queried him, he replied (with a fear-tinged voice full of gravitas), "There's no limit to what he could do. He could destroy the Earth." And fourthly, during his departing soliloquy, Klaatu informed the assembled crowd that the roving robotic police force could reduce Earth "to a burned-out cinder." However, again, atomic weapons were never mentioned, and the precise nature of the Federation's planet-killing power is left (tantalizingly) unstated. ${ }^{3}$

The onscreen ignoring of Earth's atomics was also highlighted via omission when Klaatu (in an agitated, confessing mood) and (an anxious) Helen Benson became trapped inside the stalled Department of Commerce lift because "the electricity's been neutralized all over the world" lasting for "thirty minutes." No mention of atomics was made onscreen whilst their offscreen conversation is never revealed. Later, when Helen desperately tried to stop her (Judas-like) fiancé Tom Stevens (Hugh Marlowe) from betraying (the Christic) Klaatu to the military, the topic of atomics was likewise ignored. Why be coy 
and repeatedly eschew the atomic topic if this was the (supposedly) serious message of the film? Consequently, given this coy reluctance coupled with the severe audiovisual avoidance of banning atomic energy or weapons (see Section 4), the anti-nuclear premise confidently proffered by commentators is severely diminished and becomes problematic. However, just how serious a threat to the alien Federation was Earth's atomics?

\section{Earth's Atomics Are Nascent and Not Serious Threats to the Federation}

Earth's atomics-cum-rocket technology is not firmly established but only hinted at during the following Klaatu-Barnhardt encounter (see Figures 1 and 5):

Klaatu: We [he and the Federation] know from scientific observation that your planet has discovered a rudimentary kind of atomic energy (my emphasis).

Prof. Barnhardt: [Gently nods in agreement].

Klaatu: We also know that you're experimenting with rockets (my emphasis).

Prof. Barnhardt: Yes. That is true.

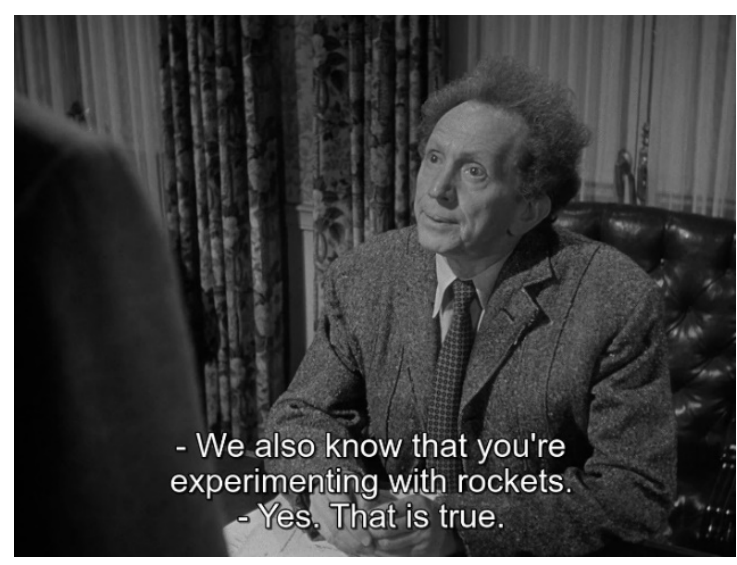

Figure 5. Klaatu's experimental rocketry comment. The Day the Earth Stood Still () 20th Century Fox. All Rights Reserved.

This brief diegetic scene is the foundational premise upon which the commentators' anti-atomic rhetoric rests (however erroneously construed). Given that Earth atomics and rocketry are only rudimentary and experimental (with Prof. Barnhardt agreeing to both facts without complaint, thereby neutralizing any claim that Earth's extant nuclear technology only appears rudimentary compared to Federation standards), they still do not threaten Federation worlds precisely because of their technological immaturity and the foreboding distances involved (see below).

Furthermore, Earth's interplanetary technology was in-process and theoretically unproven, as verified when the scientific "Savant" Prof. Barnhardt, a Nobel prize winner whom Bobby Benson deemed "the smartest man in the whole world," had not solved his celestial mechanics equation despite working on it "for weeks", according to his secretary Hilda (Marjorie Crossland). It was finally solved after Klaatu's effortless mathematical intervention on two separate occasions. Firstly, when Klaatu initially left behind some corrections for Barnhardt to finish (as a tantalizing calling card), and secondly, because Barnhardt had not solved it, he summonsed Carpenter-Klaatu who guided him to completion and subsequently testified to its efficacy for interplanetary travel.

Hypothetically speaking, even if Earth did possess atomic weaponry (but did not), as distinct from "a rudimentary kind of atomic energy" (my emphasis), coupled with "experimenting with rockets" (my emphasis), and temporarily ignoring the Gort-enforced "Pax Klaatu" (Sweeney 2003, p. 216) which would have easily eliminated the problem, it still remains a non-serious threat to the Federation, and for three basic reasons. Firstly, no Earth-built atomic bombs or interplanetary rocketry were audiovisually depicted (see 
Section 3); albeit, when Klaatu mentioned "atomic power" the young Bobby Benson automatically associated it with "bombs" (see Section 7 below).

Secondly, Klaatu's concern was future focused, namely, "soon [but not now] one of your nations will [but not yet] apply atomic energy [not bombs] to spaceships" (my emphasis; see Figure 1), what amounted to Federation anxiety over Earth's potential (but not current) interstellar propulsion capabilities. Any advanced interplanetary technology would eventually lead to an already squabbling, violent, and aggressive humanity "escaping" their quarantine-like planetary containment and disturb peaceful Federation planets. Thus, Klaatu's diplomatic mission-cum-ultimatum would effectively be cosmic preparation not punishment, a friendly warning about a pre-existing peace-enforcement system, not an invasion to deliver an embryonic execution order.

Regrettably, many commentators erroneously interpreted Klaatu's phrase, "apply atomic energy to spaceships" (i.e., for interstellar propulsion) to mean "put atomic bombs on a rocket" (Underhill 2013, p. 24), that is, to weaponize it, and thus Earth's militaristic "atomic tinkering threatens ... the cosmos itself" (Boyer 2016, p. 77; my emphasis). However, given humanity's rudimentary atomic energy and experimental rocketry, why would any Earth nation launch atomic bombs (as opposed to using atomic engines, nuclear instrumentation, or radiological experimentation equipment) into outer space at the very dawn of human interplanetary spaceflight? It is unlikely for public safety reasons alone, which could involve community uproar about radiation safety as depicted in Destination Moon (Pichel 1950), until reliability, controllability, and efficacy are achieved. Thus avoiding endangering-cum-fouling planet Earth (and only then are potential military applications appropriate).

Thirdly, compared to 1950s Earth, Federation capabilities are awesome and unmatched, as demonstrated by: (a) Klaatu's 250-million-mile journey to Earth, (b) Gort effortlessly turning the military's rifles, artillery, and tank into amorphous lumps of molten metal or vaporized them, (c) Klaatu's somewhat condescending comment about Earth's "primitive tanks and planes," (d) his precise worldwide electricity neutralizing ability, (e) Klaatu's superior biological health-cum-longevity (looks " 35,38 "-years-old but is " 78 " with a life expectancy of "130"), (f) his advanced mathematical intelligence, especially when contrasted with his quasi-condescending(?) comment to Bobby Benson about the Nobel prize-winning Prof. Barnhardt, namely, "He just needs a little help," (g) advanced alien robotics (Gort) and artificial intelligence (onboard voice-activated "computer"), (h) impregnable metallurgy (used in the construction of Gort and the spaceship), (i) advanced spaceship design and speed $(4000+\mathrm{mph}),(\mathrm{j})$ extensive interplanetary knowledge due to his interstellar travelling experience, (k) advanced language-acquisition ability, (l) planet-killing power capable of reducing Earth to a "burned-out cinder," (m) laser-like disintegrator beam, (n) quickhealing salve and advanced medicine (which made one medic feel like "a third-class witch doctor"), (o) interplanetary monitoring technology, (p) advanced personal trackers, (q) biological resurrection machinery (hi-tech holiness?), (r) trackless trains, (s) unique otherworldly diamonds, and (t) other implied but unrevealed Federation wonders (technological, sociocultural, and religious involving Klaatu's deity "the Almighty Spirit").

As such, it is not too surprising to find 1950s film reviewers like Bosley Crowthers (1951, npn) of The New York Times refer to the Federation's spaceships as "those awesome contraptions that comes whirring in from outer space, humming and glowing with energy like a gigantic neon sign, to settle to earth in fearful splendor and disembark creatures of such powers that they thoroughly belittle us mortals and put our worldly accomplishments to shame" (my emphasis). Or for contemporary physicists like Sidney Perkowitz (2010, p. 3) to claim: "This 1951 film shows technology we still can't match," or for Bryan E. Vizzini (2008, p. 35) to assess, "for all their vaunted military prowess, earth's nations scarcely hold the proverbial candle to his [Klaatu's] own capabilities," or for Anna Creadick (1999, p. 287) to note, "contrary to dominant readings of '50s sci-fi, none of our earthly "institutions" have been able to respond to the [alien] crisis." In short, Earth was the equivalent of "a helpless third world colony" (Sweeney 2003, p. 216) unable to cooperate with rival nations, 
let alone threaten the superior unified Federation planets with their hard-wired robotic policemen who, "At the first sign of violence ... act automatically against the aggressor". Indeed, Earth's comparative technological impotency was highlighted by a delightful one-upmanship conversation about the spaceship's speed. When Bobby Benson guessed it was "about a thousand miles an hour," Carpenter-Klaatu (with a smug smile and a hint of boasting) corrected him saying, "Maybe 4000 miles an hour. And outside the Earth's atmosphere, a good deal faster" (see Figure 6). This aeronautical fact was verified three times onscreen when (a) an excited British radar operator (Eric Corrie) stated that the unidentified object's approaching speed was "about 4000" and opined, "That can't be aircraft. Must be a buzz bomb," (b) when British Lieutenant Ferris (Michael Ferris) using loud military parlance reported, "four zero zero zero miles an hour" (auditorily underscored by the triple " $\mathrm{z}$ " alliteration), and (c) when Hoosier-accented radio journalist Elmer Davis (himself) confidently stated, "a rate of 4000 miles an hour".
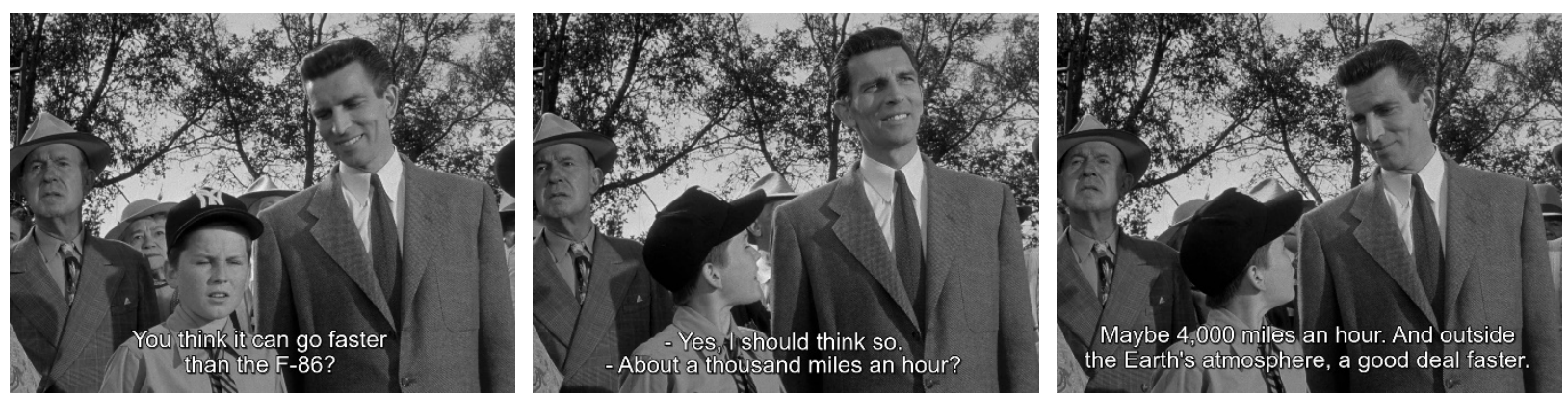

Figure 6. Klaatu's smug countenance. The Day the Earth Stood Still @ 20th Century Fox. All Rights Reserved.

Klaatu had revealed its "incredible speed" (stated by a BBC radio announcer [John Burton]) when Bobby had enthusiastically asked if the "F-86" could go faster than the spaceship, which was itself a subtle one-upmanship opportunity easily missed by audiences. ${ }^{5}$ This correct aircraft designation was Bobby's dialogic shorthand for the real-world North American F-86 Sabre (aka Sabrejet), a transonic, $35^{\circ}$ swept-wing jet fighter that was first flown on 1 October 1947, went into production on 18 May 1948, was commissioned by the USAF in 1949, and quickly became a military mainstay during the 1950-1953 Korean War (Newdick 2010, p. 142). It had a maximum speed of 601 miles per hour at 35,000 feet (Green and Swanborough 2004, p. 449) which was 85\% slower than Klaatu's 4000 miles per hour atomic-powered spaceship (Earth-bound, but off-world "a good deal faster"). Since Klaatu uses an atomic-powered spaceship, it begs the question: Just how anti-atomic was Klaatu?

\section{Klaatu Is Not Anti-Atomic But Proudly Pro-Atomic}

Klaatu is not anti-atomic in any ideological, political, sociocultural, religious, or practical sense; instead, he is proudly pro-atomic in intention, word, and deed, which is frequently overlooked, downplayed, or misinterpreted by commentators. Clear evidence of his pro-atomic proclivity is indicated when a curious Bobby Benson at the spaceship landing site excitedly asked, "What do you think makes it go?," and the incognito Klaatu as Mr. Carpenter cautiously glances sideways and said, "Well aah, a highly developed form of atomic power I should imagine" (my emphasis; see Figure 2). His (presumably) truthful but guarded words deflected exposure of his on-the-run alien identity ensconced amidst a fearful crowd, armed military, gun-toting services police, and a sensation-hungry reporter deliberately exploiting fearfulness. However, when Bobby retorted, "I thought that ["atomic power"] was only for bombs," Klaatu instantly displayed a disapproving face and thoughtfully corrected Bobby with, "No. No it's for lots of other things too" (see Figure 7). Furthermore, throughout the film, Klaatu never displayed disapproval, fear, loathing, or advocates the banning of atomic bombs, power, energy, or experimentation, thus further underscoring his pro-atomic support in this via negativa fashion. 


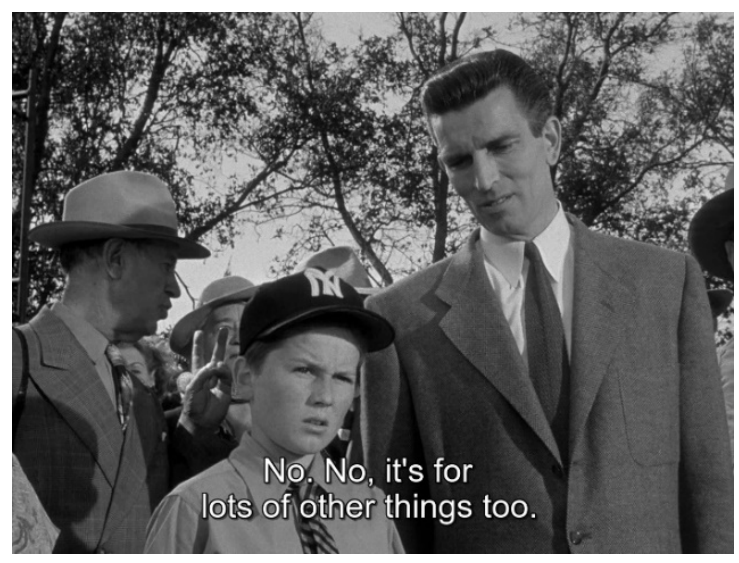

Figure 7. Klaatu's disapproving face at Bobby's 'bombs' comment. The Day the Earth Stood Still () 20th Century Fox. All Rights Reserved.

Klaatu's pro-atomic-powered aeronautical stance was also indirectly demonstrated inside Prof. Barnhardt's unoccupied study wherein, unasked, he promptly corrected Barnhardt's (in-process) celestial mechanics equation, what Bobby Benson called "his arithmetic" (see Figure 8). Later, a disappointed Carpenter-Klaatu guided the Nobel prizewinning professor towards its eventual solution, and when Prof. Barnhardt tentatively asked, "Have you tested this theory?", Klaatu confidently replied (with a tone of restrained revelation-cum-smile), "I find it works well enough to get me from one planet to another ... I am Klaatu." Such crucial alien assistance belies the claim that Klaatu "put a forcible halt to earth's nuclear experimentation" (Rovin 1977, p. 86; my emphasis) or that he "warns Earth that it must not develop rocket-delivered nuclear weapons" (Bainbridge 2017, p. 159; my emphasis) simply because Klaatu twice helped Prof. Barnhardt mathematically secure humanity's interstellar travelling future (presumably in Earth-built atomic-powered spaceships).

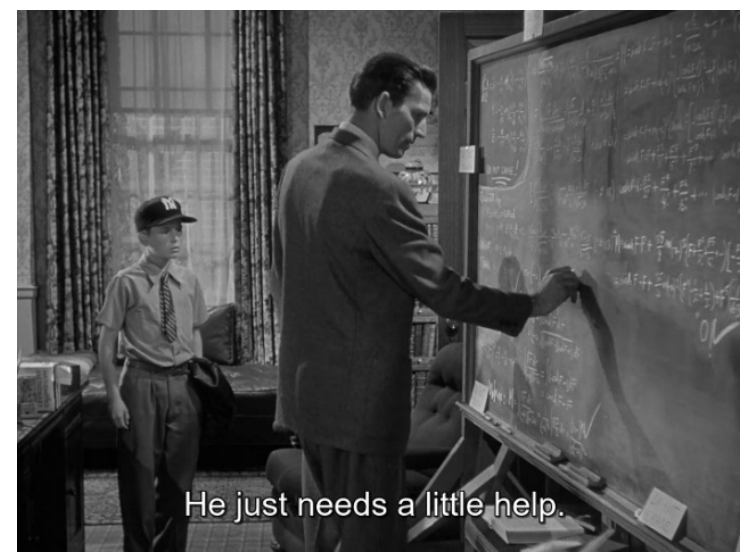

Figure 8. Klaatu correcting Prof. Barnhardt's equation. The Day the Earth Stood Still $\odot$ 20th Century Fox. All Rights Reserved.

Furthermore, Klaatu referred to Earth's "rudimentary kind of atomic energy" that differed from his "highly developed form of atomic power", but neither statement was anti-atomic; the latter comment confirms Klaatu's pro-atomic acceptance because this is what powers his own spaceship (and the spaceships of Gort's roving robotic peers). One speculatively imagines that when humanity sufficiently matures and eschews aggression and violence (thus circumventing police-triggered purging), the Federation would grant humanity superior atomics for better power production and control, for non-military scientific purposes, and for deeper interstellar exploration possibilities. Echoes of these themes occurred within Star Trek: The Motion Picture (Wise 1979), and also within Star 
Trek: First Contact (Frakes 1996) featuring Earth's first contact with the technologically and intellectually superior Vulcan alien race who had painstakingly mastered their aggressive emotional sides to ultimately achieve their peaceful, super-rational, paradisiacal society.

\section{Conclusions}

Robert Wise's The Day the Earth Stood Still (1951) contains either none, or very brief references to atomic energy, nuclear weaponry, banning atomic bombs, or the suppression of Earth's nuclear experimentation, whilst emissary Klaatu clearly demonstrates via intention, word, and deed that he is profoundly pro-atomic, not anti-atomic as frequently touted within both the critical and popular literatures. Klaatu's position was clear, strong, and convincing but, regrettably, his unwarranted role as a proverbial poster boy for antiatomics has blinded many a viewer to the filmic truth. The frequent misinterpretations led to faulty film criticism underpinned by overzealous critics making too many assumptions, inventing facts, and jumping to conclusions. Such a rose-colored-glasses effect alone is worthy of further scholarly investigation, especially during the post-truth period of Donald Trump. The resultant academic payoff will be the discovery of multiple revelations that transcend the uncritical parroting of others' (frequently tainted) viewer comments rooted in extra-filmic sources. Further research into alien first-contact scenarios, robotic artificial intelligence, and the moral make-up of the SF universe is warranted and long overdue.

Funding: This research received no external funding.

Conflicts of Interest: The author declares no conflict of interest.

\section{Notes}

1 Within both Robert Wise's (1951) film and Edmund H. North's (1951) script, Klaatu employed the term "atomic" whereas many commentators employed the term "nuclear." Physics-wise, they refer to two different energy processes (see King 2018), namely: (a) "fission" (the splitting of atoms in a chain reaction fashion) and (b) "fusion" (the fusing of atoms in a binding fashion). Since both processes achieve the same basic outcome (i.e., massive releases of subatomic energy), both terms will be treated herein as essentially interchangeable. However, where appropriate, "atomics" will be employed to honour both Wise's and North's filmmaking intentions, and also to avoid awkward compound terms such as "atomic/nuclear", "nuclear/atomic", or other creative neologisms.

2 Brosnan had inappropriately fused parts of Klaatu's public soliloquy at film's end with parts of Klaatu's private conversation with Prof. Barnhardt depicted mid-film.

3 One imagines the spaceship equivalent of Gort's visor laser being deployed, as depicted in the "Are We Long For This World?" newspaper graphic shown during the boarding house breakfast table scene.

$4 \quad$ For an exploration of the subtextual religious crafting of The Day the Earth Stood Still (Wise 1951) see Kozlovic (2021).

5 Bobby's interest in airplanes is inferred from his bedroom wall posters depicting various aircraft, and a small model airplane sitting atop his bedside table.

\section{References}

Bainbridge, William Sims. 2017. Dynamic Secularization: Information Technology and the Tension Between Religion and Science. Cham: Springer.

Barone, Dennis. 1996. Klaatu was No Angel: A Historical-contextual Analysis of The Day the Earth Stood Still. Studies in the Humanities 23: 202-12.

Bates, Harry. 1940. Farewell to the Master. Astounding Science-Fiction 26: 58-87.

Bell-Metereau, Rebecca. 2006. The Capital Shape of Science Fiction Heroes to Come. In Cinema and Modernity. Edited by Murray Pomerance. New Brunswick: Rutgers University Press, pp. 110-29.

Booker, M. Keith. 2001. Monsters, Mushroom Clouds, and the Cold War: American Science Fiction and the Roots of Postmodernism, 1946-1964. Westport: Greenwood Press.

Boyer, Paul. 2016. Sixty Years and Counting: Nuclear Themes in American Culture, 1945 to the Present. In Understanding the Imaginary War: Culture, Thought and Nuclear Conflict, 1945-90. Edited by Matthew Grant and Benjamin Ziemann. Manchester: Manchester University Press, pp. 75-91.

Brannon, Fred C., dir. 1950. Flying Disc Man from Mars. Los Angeles: Republic Pictures.

Brosnan, John. 1978. Future Tense: The Cinema of Science Fiction. London: Macdonald and Jane's. 
Bywater, Tim, and Thomas Sobchack. 1989. An Introduction to Film Criticism: Major Critical Approaches to Narrative Film. New York: Longman.

Çetiner-Öktem, Züleyha. 2019. The Apocalyptic Chronotope in "Farewell to the Master" and The Day the Earth Stood Still. Mediterranean Journal of Humanities 9: 113-26. [CrossRef]

Copier, Laura, and Caroline Vander Stichele. 2016. Death and Disaster: 2012 Meets Noah. In Close Encounters between Bible and Film: An Interdisciplinary Engagement. Edited by Laura Copier and Caroline Vander Stichele. Atlanta: SBL Press, pp. 155-71.

Cornea, Christine. 2017. From Isolationism to Globalism: An Overview of Politics and Ethics in the Hollywood Science Fiction Film. In Science Fiction, Ethics and the Human Condition. Edited by Christian Baron, Peter Nicolai Halvorsen and Christine Cornea. Cham: Springer, pp. 159-79.

Cowan, Douglas E. 2009. Seeing the Saviour in the Stars: Religion, Conformity, and The Day the Earth Stood Still. Journal of Religion and Popular Culture 21: 3-30. [CrossRef]

Cranny-Francis, Anne. 2007. Mapping Cultural Auracy: The Sonic Politics of The Day the Earth Stood Still. Social Semiotics 17: 87-110. [CrossRef]

Creadick, Anna. 1999. Incredible/Shrinking Men: Masculinity and Atomic Anxiety in American Postwar Science-fiction Film. In Fear Itself: Enemies Real \& Imagined in American Culture. Edited by Nancy Lusignan Schultz. West Lafayette: Purdue University Press, pp. 285-300.

Crowthers, Bosley. 1951. The Screen in Review; Emissary From Planet Visits Mayfair Theatre in 'Day the Earth Stood Still'. The New York Times, September 19. Available online: https:/ / www.nytimes.com/1951/09/19/archives/the-screen-in-review-emissary-fromplanet-visits-mayfair-theatre-in.html (accessed on 26 August 2021).

Cusack, Carole M. 2014. Apocalypse in Early UFO and Alien-based Religions: Christian and Theosophical Themes. In Modernism, Christianity and Apocalypse. Edited by Erik Tonning, Matthew Feldman and David Addyman. Leiden: Brill, pp. 339-53.

Derrickson, Scott, dir. 2008. The Day the Earth Stood Still. Los Angeles: Twentieth Century Fox.

Dotson, Daniel. 2009. Portrayal of Physicists in Fictional Works. CLCWeb: Comparative Literature and Culture 11: 1-15. [CrossRef]

Eagan, Daniel. 2010. America's Film Legacy: The Authoritative Guide to the Landmark Movies in the National Film Registry. New York: Continuum.

Eldridge, David. 2006. 'There is Hope for the Future': Retrospective Visions of the Bomb in 1950s Hollywood. Historical Journal of Film, Radio and Television 26: 295-309. [CrossRef]

Evans, Joyce A. 1998. Celluloid Mushroom Clouds: Hollywood and the Atomic Bomb. Boulder: Westview Press.

Fischer, Dennis. 2000. Science Fiction Film Directors, 1895-1998. Jefferson: McFarland.

Frakes, Jonathan, dir. 1996. Star Trek: First Contact. Hollywood: Paramount Pictures.

Frank, Alan G. 1974. The Movie Treasury: Horror Movies: Tales of Terror in Cinema. London: Octopus Books.

Frank, Alan G. 1976. The Movie Treasury: Monsters E Vampires. London: Octopus Books.

Frank, Alan G. 1978. Screen Trips. In Encyclopedia of Science Fiction. Edited by Robert Holdstock. London: Octopus Books, pp. $68-85$.

Frank, Alan G. 1982. The Science Fiction and Fantasy Film Handbook. London: The Anchor Press.

Freedman, Carl. 1998. Kubrick's 2001 and the Possibility of a Science-fiction Cinema. Science Fiction Studies 25: 300-18.

Fuller, Samuel, dir. 1954. Hell and High Water. Los Angeles: Twentieth Century Fox.

George, Susan A. 2000. Space for Resistance: The Disruption of the American Frontier Myth in 1950s Science Fiction Films. In Space and Beyond: The Frontier Theme in Science Fiction. Edited by Gary Westfahl. Westport: Greenwood Press, pp. 77-83.

George, Susan A. 2008. Invaders of the Cold War: Generic Disruptions and Shifting Gender Roles in The Day the Earth Stood Still. In Why We Fought: America's Wars in Film and History. Edited by Peter C. Rollins and John E. O'Connor. Lexington: The University Press of Kentucky, pp. 349-66.

Green, William, and Gordon Swanborough. 2004. The Complete Book of Fighters: An Illustrated Encyclopedia of Every Fighter Aircraft Built and Flown. London: Greenwich Editions.

Hefner, Brooks E. 2014. Milland Alone: The End of the System, Post-Studio Stardom, and the Total Auteur. Journal of Film and Video 66: 3-18. [CrossRef]

Hunter, Robert E. 2009. Expecting the Unexpected: Nuclear Terrorism in 1950s Hollywood Films. In The Atomic Bomb and American Society: New Perspectives. Edited by Rosemary B. Mariner and G. Kurt Piehler. Knoxville: The University of Tennessee Press, pp. 211-37.

Johnson, Coralie C. 2007. The Humanist Approach to Film: My Brilliant Career. Available online: http://wildwoodpress.org/thehumanist-approach-to-film-my-brilliant-career/ (accessed on 13 June 2021).

King, George C. 2018. Physics of Energy Sources. Chichester: John Wiley \& Sons.

Kozlovic, Anton Karl. 2021. Sacred Subtexts and the Biblical Buttressing of Klaatu as a Christ Figure in The Day the Earth Stood Still (1951). In TET Clark Handbook of Jesus and Film. Edited by Richad Walsh. London: T\&T Clark, pp. 225-36.

Longuski, Jim. 2007. The Seven Secrets of How to Think Like a Rocket Scientist. New York: Copernicus Books.

Luokkala, Barry B. 2019. Exploring Science through Science Fiction, 2nd ed. Cham: Springer.

Mann, George. 2001. The Mammoth Encyclopedia of Science Fiction. London: Robinson.

Mathis, John R. 2013. Atomic Cinema in America: Historical and Cultural Analysis of a New Film Genre That Reflected the Nuclear Zeitgeist of the Cold War (1945-1989). Ph.D. Dissertation, Salve Regina University, Newport, RI, USA, April 26.

Newdick, Thomas. 2010. Aircraft of the Cold War 1945-1991. London: Amber Books. 
North, Edmund H. 1951. “The Day the Earth Stood Still” by Edmund H. North. Revised Final Draft, February 21. Available online: http:/ / www.scifiscripts.com/scripts/TheDayTheEarthStoodSTill.html (accessed on 13 June 2021).

Perkowitz, Sidney. 2010. Hollywood Science: Movies, Science, and the End of the World. New York: Columbia University Press.

Pichel, Irving. 1950. Destination Moon. Los Angeles: George Pal Productions.

Possamai, Adam, and Alphia Possamai-Inesedy. 2014. Cultural Framing of Risk and Religion Within Science Fiction Narratives. Journal for the Academic Study of Religion 27: 94-113. [CrossRef]

Rivkin, Malcolm D. 1951. The Day the Earth Stood Still at the RKO Boston. The Harvard Crimson, October 13. Available online: http:/ / www.thecrimson.com/article/1951/10/13/the-day-the-earth-stood-still/ (accessed on 13 June 2021).

Rosewarne, Lauren. 2020. Why We Remake: The Politics, Economics and Emotions of Film and TV Remakes. London: Routledge.

Rovin, Jeff. 1977. From the Land Beyond: The Films of Willis O'Brien and Ray Harryhausen. New York: Berkley Wind Books.

Schuster, Harold D., dir. 1954. Port of Hell. Los Angeles: William F. Broidy Production.

Sears, Fred F., dir. 1953. The 49th Man. Los Angeles: Sam Katzman Productions.

Shaheen, Jack G. 1978. Nuclear War Films. Carbondale: Southern Illinois University Press.

Shapiro, Jerome F. 2002. Atomic Bomb Cinema: The Apocalyptic Imagination on Film. New York: Routledge.

Shaw, James. 1998. The Day the Earth Stood Still: Dramatizing a Political Tract. Creative Screenwriting 5: 50-53.

Shearer, Stephen Michael. 2006. Patricia Neal: An Unquiet Life. Lexington: The University of Kentucky Press.

Siegel, Don, dir. 1956. Invasion of the Body Snatchers. Los Angeles: Allied Artists Pictures/Walter Wanger Pictures.

Stal. 1951. The Day the Earth Stood Still. Variety 183: 6.

Stanley, O’Brien, Nicki L. Michalski, Lane “Doc" Roth, and Steven J. Zani. 2018. Martian Pictures: Analyzing the Cinema of the Red Planet. Jefferson: McFarland.

Strada, Michael J. 1986. Kaleidoscopic Nuclear Images of the Fifties. Journal of Popular Culture 20: 179-98. [CrossRef]

Suh, Jungkyu. 2021. Nuclear Eventuality: How the Nuclear Bomb Contaminated the Present with the Future. Ph.D. Dissertation, Purdue University, West Lafayette, IN, USA, May.

Suid, Lawrence H. 2002. Guts \& Glory: The Making of the American Military Image in Film, rev. ed. Lexington: The University Press of Kentucky.

Sweeney, Gael. 2003. Impatient with Stupidity: Alien Imperialism in The Day the Earth Stood Still. In Closely Watched Brains, 2nd ed. Edited by Murray Pomerance and John Sakeris. Boston: Pearson Education, pp. 215-29.

Taylor, Bryan C. 2003. “Our Bruised Arms Hung Up as Monuments": Nuclear Iconography in Post-Cold War Culture. Critical Studies in Media Communication 20: 1-34. [CrossRef]

Telotte, J. P. 2001. Science Fiction Film. Cambridge: Cambridge University Press.

Towlson, Jon. 2014. Subversive Horror Cinema: Countercultural Messages of Films from Frankenstein to the Present. Jefferson: McFarland.

Underhill, Bethany. 2013. Creature Features and Consensus: Genre Fiction's Critique of Postwar Atomic Technology. M.A. Dissertation, University of Nevada, Reno, NV, USA, December.

Variety Staff. 1950. The Day the Earth Stood Still. Variety, December 31. Available online: https://variety.com/1950/film/reviews/theday-the-earth-stood-still-1200416871/ (accessed on 26 August 2021).

Vizzini, Bryan E. 2008. Cold War Fears, Cold War Passions: Conservatives and Liberals Square Off in 1950s Science Fiction. Quarterly Review of Film and Video 26: 28-39. [CrossRef]

von Gunden, Kenneth, and Stuart H. Stock. 1982. Twenty All-time Great Science Fiction Films. New York: Arlington House.

Walsh, Kenneth T. 2017. Celebrity in Chief: A History of the Presidents and the Culture of Stardom: With a New Epilogue on Hillary and "The Donald". London: Routledge.

Weart, Spencer R. 1988. Nuclear Fear: A History of Images. Cambridge: Harvard University Press.

Wise, Robert, dir. 1951. The Day the Earth Stood Still. Los Angeles: Twentieth Century Fox.

Wise, Robert, dir. 1979. Star Trek: The Motion Picture. Hollywood: Paramount Pictures.

Wojcik, Daniel. 2003. Apocalyptic and Millenarian Aspects of American UFOism. In UFO Religions. Edited by Christopher Partridge. London: Routledge, pp. 274-300.

Zebrowski, George. 1974. Science Fiction and the Visual Media. In Science Fiction, Today and Tomorrow. Edited by Reginald Bretnor. Baltimore: Penguin, pp. 29-40. 